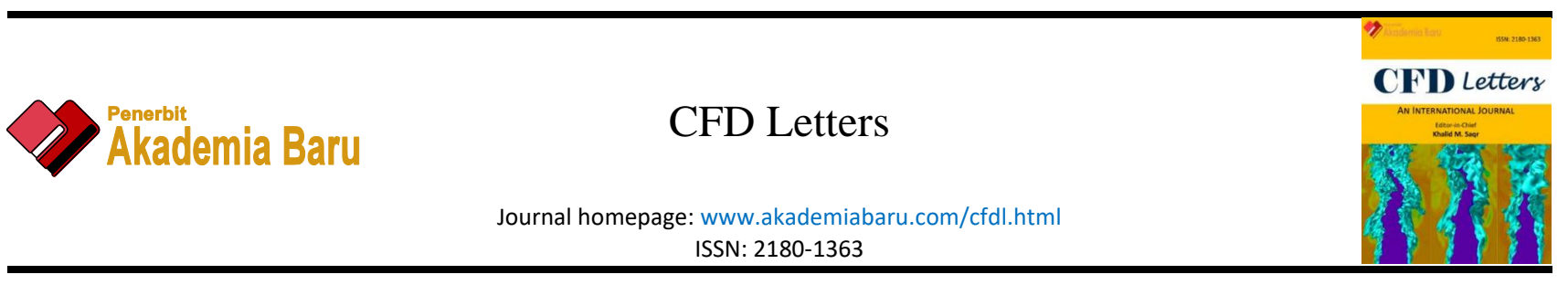

\title{
Gust Load Alleviation of Flexible Composite Wing
}

\author{
Mohamed Ibren ${ }^{1}$, Erwin Sulaeman ${ }^{1,}{ }^{*}$, Amelda D. Andan ${ }^{1}$, Yulfian Aminanda ${ }^{2}$, A.K.A Halim ${ }^{1,3}$ \\ Department of Mechanical Engineering, Faculty of Engineering, International Islamic University Malaysia, Kuala Lumpur, 53100 Malaysia \\ Department of Mechanical Engineering, Faculty of Engineering, Universiti Teknologi Brunei, BE1410 Brunei Darussalam \\ 3 Department of Aeronautical Engineering, Faculty of Mechanical and Manufacturing Engineering, Universiti Tun Hussein Onn Malaysia, Johor, \\ 86400 Malaysia
}

\section{ARTICLE INFO}

\section{Article history:}

Received 20 February 2020

Received in revised form 18 April 2020

Accepted 22 April 2020

Available online 30 April 2020

\section{ABSTRACT}

Gust load due to atmospheric turbulence is mandatory to be considered in aircraft analysis as part of airworthiness requirement. This safety related issue becomes more relevant recently in relation to the global warming that induces more frequent and extreme atmospheric disturbances encountered during air transportation. A direct application of gust load on the wing structural analysis, however, is not recommended since it will result in a significant weight increase due to the overdesign of the wing structure. At this point, the gust load alleviation plays an important role to effectively utilize the wing structural flexibility without ignoring the safety issue. In the present work, a method to alleviate the wing gust load is proposed by considering different configurations of the wing planform, wing sweep angle, wing dihedral angle and composite material layers. The objective of the study is to minimize the wing root bending moment due to the gust. The gust load analysis of the Kim-Hwang's wing model will be used and the results are compared to the literature for the validation purpose. A finite element approach is used to simulate the wing structure in combination with the doublet lattice method to model the wing aerodynamics. It is found that the wing dihedral angle plays insignificant changes to the wing root bending moment due to the gust load. The wing sweep angle, however, gives significant changes to the wing root bending moment. For the present configuration, the optimum swept back configuration with a $45^{\circ}$ sweep angle and optimum composite lay-up showed an average decrease of the bending moment by $12 \%$ for frequency range of 0 to $100 \mathrm{~Hz}$.

Keywords:

Fluid-structure interaction; gust load; aeroelasticity; dynamic response; composite flexible wing

Copyright @ 2020 PENERBIT AKADEMIA BARU - All rights reserved

\section{Introduction}

Gust loads are encountered whenever an aircraft faces unexpected strong wind either laterally, vertically or head on. Furthermore, angle of attack increases or decreases as the aircraft experience gust load. Small aircraft response to the gust loads faster as compared to the larger aircraft; this

\footnotetext{
* Corresponding author.

E-mail address: esulaeman@iium.edu.my (Erwin Sulaeman)
}

https://doi.org/10.37934/cfdl.12.4.7989 
provides the facts that the smaller aircrafts are more likely to face structural failure if the gust load exceeds its capacity. Moreover, increasing the load experience by the aircraft structure will cause a greater vertical acceleration thus increase structural stress.

The wing configuration can also affect the gust load experience by the aircraft. For instance, the aft-swept wing will bend up when encountering the gust load, which twists the wing hence reducing the angle of attack for the outer part of the wing. Therefore, the total lift on the outboard wing is lowered. Therefore, the aft-swept wing lowers the loads to some extent.

\subsection{Previous Studies}

With the fast-paced progress of aircraft industry, the gust load analysis has shown to be one of the crucial elements in the design of aircraft as shown by various authors [1-15]. Many researches aim to explore and contribute to the industry of large transport aircraft and unmanned air vehicle. A large number of papers have been focused on analysis of large aspect ratio wings and divergence. The study conducted by Rodden and Johnson [11] discovered that finite gust disturbances could bring the flying wing to a strong unstable divergence response, based on the effects of its flexibility, distribution of load as well as disturbance due to gust. Kim and Hwang [8] suggested that high aspect ratio wing and flexible wing structures are prone to failure when subjected to gust disturbance. Yu, Yang, Wang and Guo [16] stated that gust models can be analyzed as discrete gust, which is the simpler profile, or as continuous gust which follows Von Karman concept mostly.

The study by Ehlers and Weisshaar [3] has shown a method to use piezoelectric actuators for wing surface divergence control. Another research focus is the analysis of control issues in gust load alleviation (GLA). The research performed by McLean [9], for example, found that to improve flying class while an aircraft is affected by gust, the use of active control will promote deceleration. A similar research conducted by Cook [1] showed that a robust controller gives satisfactory performance when contrasting closed-loop responses with open-loop dynamics. The research by Dillsaver et al., [2] utilized linear-quadratic-Gaussian (LQG) gust load alleviation control for a rigidelastic coupling flexible aircraft. The total wing deflection reduction was by $47 \%$. Yet another focus of the area is the usage of intelligent materials, such as piezoelectric actuators.

Research conducted by Ehlers and Weisshaar [3] focused on the material for wing surface divergence control and used it to control flight attitude by transforming the wing surface form. Yet another usage of piezoelectric actuators is the synthesis of a flutter suppression control law and optimizes actuators positions as discussed by Lin, Crawley, and Heeg [14]. Guo et al., [5] stated that composite materials are used in the aircraft structure because of its high specific stiffness and strength. Above all that, Guo et al., [5] proclaims that, beside the high specific stiffness and strength of the materials, aeroelastic constraints such aeroelastic stability and gust response need to be considered. Guo, Monteros and Liu [6] claimed that some of the aircraft experience critical gust load as compared to the manoeuver load and thus modern aircraft structure are improved by introducing composite materials. Gauthier-Perron and Drela [4] proposed that increasing the bendtwist coupling will reduce the span wise bending moment by approximately $20 \%$ to $45 \%$. Tajuddin et al., [17] investigated the flow behaviour on wing with high angle of attack. Munshi et al., [18] studied the flow on ONERA wing due to winglet which may affect also aerodynamic wing load distribution.

A large percentage of GLA research is directed to use of various state-of-the-art control methods to alleviate vertical acceleration by deflecting conventional control surfaces, but more research can be done from another point of view. This project will focus on usage of structural flexibility of the wing, and proper arrangement of composite material layers. 


\subsection{Present Work}

Gust load alleviation is still a subject undergoing intense study until today. Early investigations focus mainly on the passive load alleviation by designing the structural stiffness and wing planform in such a way that partially reduce the effect of gust on the particularly wing root stress level, i.e. by redistribution of the load along the wing span. With the advancement of control surface technology as a means to actively alleviate the gust load, additional reduction of the gust load is achieved. The conventional control surface, however, exhibits limitation in the deflection angle and frequencies such that it is still not enough to reduce the gust load. Therefore, there is still a need to find new technologies to overcome the large load peak due to the gust disturbance.

In this present work, the gust profile is assumed to follow stationary Gaussian random process because of the small interval of time during the impact. This also helps to simplify the gust analysis which is more complex in actual condition. However simpler it is, the stationary Gaussian random process is considered to be more realistic than the discrete gust analysis. Moreover, this provides an easy mathematical relationship between the power spectrum density and the time history of the turbulence. The generated power spectral density (PSD) of the gust is related to the inputs by differential equation for the frequency domain function whereas the time domain requires a more complex and tedious numerical integrations. Therefore, Von Karman gust profile is selected in this study because of its better fit to the experimental data as compared to the Dryden gust profile.

\section{Methodology}

Literature review to learn state of the art on Gust Load Alleviation (GLA) will be conducted in the beginning of the present research. The passive and active load alleviation was thoroughly investigated. The composite materials are included in the GLA study in order to find the most robust technique. The review includes the progress in aerodynamic of composite flexible wing.

Based on the literature review, a typical wing model is selected from one the literature review as the baseline model. A wing sizing is performed based on the parameters given by the authors of that paper. The result of the sizing is the finite element data of the wing structure. The wing weight is saved as the baseline data.

The gust load analysis for the baseline wing configuration $[90 / \pm 45 / 0]_{2 s}$ was then performed and the dynamic response result recorded. The gust load analysis of the latest model was compared to the literature for validation purpose. The first modification to the baseline model was conducted by replacing the baseline with other wing configurations. The second and third wing configurations used are $\left[0_{4} / 45 / 0_{2} /-45\right]_{s}$ and $\left[0_{4} /-45 / 0_{2} / 45\right]_{s}$ respectively. Similar sizing procedure and gust load analysis was conducted. The results of both baseline and modified wing models was compared and analyzed for different wing configurations.

\subsection{Gust Analysis}

To perform the analysis of the random gust, the profile has to be constructed and added in the MSC Nastran code. The typical gust profile is always unpredictable and irregular in shape.

The Von Karman's mathematical expression used to construct the gust profile is presented by Hoblit [7] as follows;

$\phi(\Omega)=\sigma^{2} \frac{L}{\pi} \frac{1+8 / 3(1.339 L \Omega)^{2}}{\left[1+(1.339 L \Omega)^{2}\right]^{11 / 6}}$ 
Here $\phi(\Omega)$ is the gust PSD as a function of omega, $\Omega$ is the root mean square of the gust PSD, L is the scale of turbulence,

Moreover, the PSD values is generated numerically starting from zero frequency until $100 \mathrm{~Hz}$. The parameters used to generate PSD values were acquired from Kim and Hwang [8] and the values given are;

$V=15 \mathrm{~m} / \mathrm{s} ; \sigma=0.3048 \mathrm{~m} / \mathrm{s} ; L=762 \mathrm{~m}$

\subsection{Structural Analysis}

In this study, the gust analysis was performed by initially using the wing presented by KimHwang [8]. The initial wing followed exactly the Kim-Hwang's wing but later in the analysis, the wing was redesigned to have different swept angles as well as dihedral angle. The wing was redesigned so that the effect of wing sweep and dihedral angles towards gust analysis can be analysed too. The baseline wing presented by Kim and Hwang [8] is shown in Figure 1. The redesign wing has 5 different sweep angles as shown in Figure 2 including backward sweep angles of $+15^{0}$, $+30^{\circ}$ and $+45^{\circ}$, and forward sweep angles of $-15^{0}$ and $-30^{\circ}$.

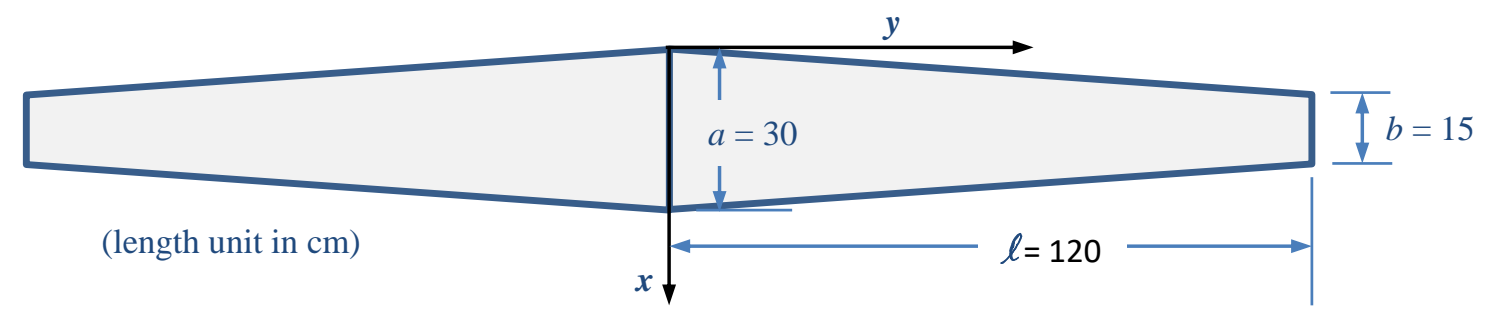

Fig. 1. Kim - Hwang Wing Model [8]
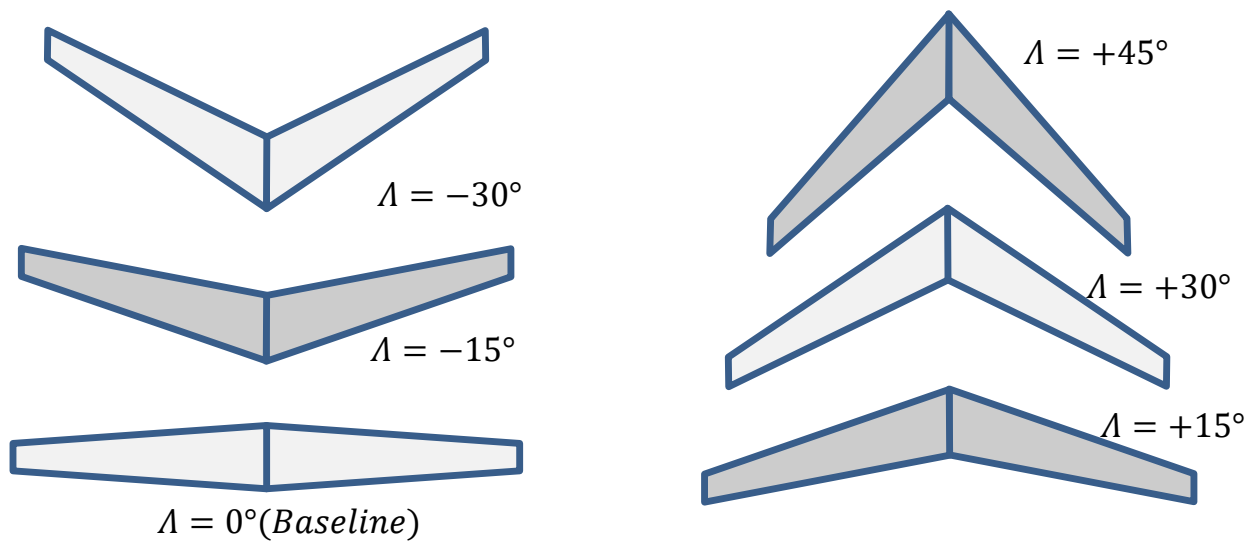

Fig. 2. Swept wing configurations investigated in the present work

The wing is geometrically untwisted and has an aspect ratio of 5.33, a taper ratio of 0.5 and wing span length of $120 \mathrm{~cm}$. The wing root and tip chord is $30 \mathrm{~cm}$ and $15 \mathrm{~cm}$ respectively. Therefore, the wing mean chord length is $22.5 \mathrm{~cm}$. The wing surface area calculated from the mean chord and the wing span is $2700 \mathrm{~cm}^{2}$.

The grids were generated using the wing's parameter, 21 grids were generated span wise whereas 4 grids were constructed along the wing chord. These provide a total of 84 grids generated along the wing surface. Furthermore, CQUAD4 panels were designed by connecting grids in pairs of four in spanwise direction. Following Kim et al., [8], there are three laminate orientations used 
including Baseline orientation which is $[90 / \pm 45 / 0]_{s}$, Orientation 2 which is $[04 / 45 / 02 /-45]_{s}$, and Orientation 3 which is $\left[0_{4} /-45 / 0_{2} / 45\right]_{s}$.

\subsection{Aerodynamic Analysis}

For the subsonic regime flow, the analysis of the unsteady aerodynamic is performed using doublet lattice method (DLM). The aerodynamic model used by doublet lattice method is trapezoidal shape. Therefore, in the present work, the wing is discretized into 80 trapezoidal shape elements. MSc Nastran [11] was used to acquire the doublet lattice method equations. For the swept wing configuration, CAERO1 was divided in two parts in order to design the inboard and outboard of the wing aerodynamic models accordingly. The flight altitude used was $10,000 \mathrm{ft}$.

\subsection{Aerodynamic - Structure Model Interpolation}

The structure and aerodynamic models are inter-connected by interpolation called spline in MSC Nastran. Since our model was design as a plate then Spline1 option, which is infinite surface spline approach, is used to specify the interpolation between the structural deformations and the aerodynamic loads.

MSC Nastran choses structural grid points to be independent whereas the aerodynamic grid points are chosen to be dependent. Therefore, two transformations are required to relate the independent and dependent grid points. First, the structural deflections are transformed to the aerodynamic grid points, and then aerodynamic forces are related with structurally equivalent forces acting on the structural grid points.

\section{Results}

The procedure of the present research involves modelling the wing structure, aerodynamics and its aeroelastic solution following the wing configuration given by Kim et al., [8]. The first attempt is to validate this work with Kim et al., [8] results via frequencies of the vibration modes.

Moreover, dynamic aeroelastic response analysis of the random gust of the modelled wing is analysed and the results of its bending moments PSD presented in detail. In addition, unsteady aerodynamic of the wing induced by a gust external load of two more composite orientation is analysed and the results elaborated well. This shows the effects of the composites orientation on the bending moments PSD.

Furthermore, different wing configurations were analysed using the optimum composite orientation. Firstly, various dihedral models including mid dihedral, straight dihedral, tip dihedral and anhedral were studied. Secondly, swept back wing models which include $15^{\circ}, 30^{\circ}$ and $45^{\circ}$ were examined as well. Finally, swept forward wing type of $15^{\circ}$ and $30^{\circ}$ angle were analysed and illustrated in this part too.

\subsection{Validation}

Table 1 below elaborates the differences of the vibrational frequency for the first six modes. The relative difference data shows a significant agreement with the results of Kim and Hwang [8]. The highest percentage difference between the data is roughly $3.8 \%$ which is less than $5 \%$ and thus acceptable. Figure 3 presents the first 6 vibration mode shapes of the baseline configuration which is similar to the mode shapes of Kim-Hwang [8]. Therefore, these provide a complete validation for 
the procedures and calculations of the dynamic aeroelastic analysis. The air density and speed of sound are based on the US Atmospheric Standard [13] at 10,000 ft altitude as used also by Kim and Hwang [8].

Table 1

Comparison of natural frequency data of Kim-Hwang's wing

\begin{tabular}{llll}
\hline Mode & $\begin{array}{l}\text { Ref. } 8 \\
(\mathrm{~Hz})\end{array}$ & $\begin{array}{l}\text { Present Work } \\
(\mathrm{Hz})\end{array}$ & $\begin{array}{l}\text { Relative } \\
\text { Difference }(\%)\end{array}$ \\
\hline 1 & 2.598 & 2.57 & 1.22213 \\
2 & 14.111 & 14.00 & 0.46113 \\
3 & 23.601 & 24.30 & 3.12156 \\
4 & 37.906 & 38.10 & 0.56086 \\
5 & 60.099 & 62.40 & 3.88254 \\
6 & 73.512 & 75.00 & 1.98588 \\
\hline
\end{tabular}
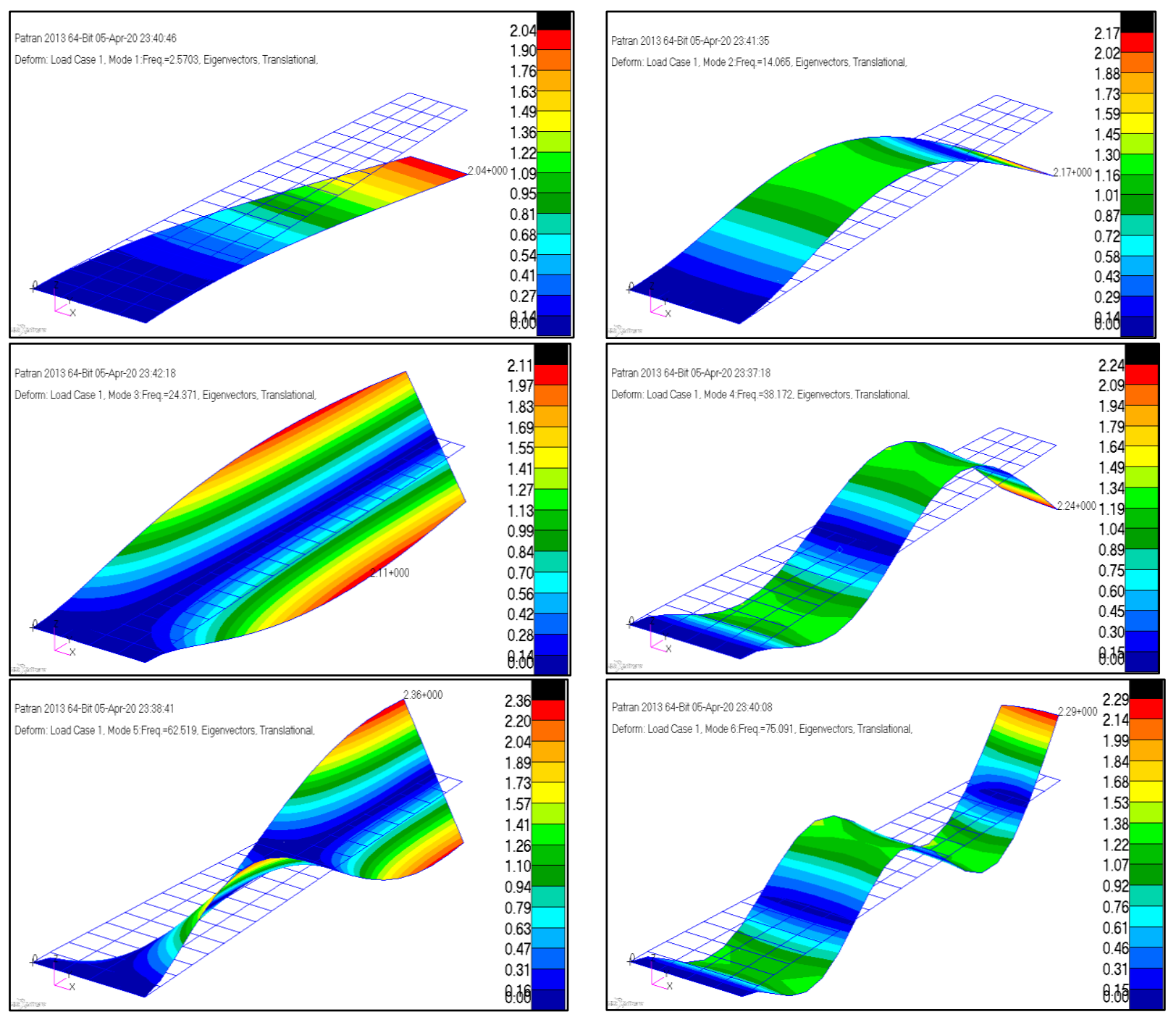

Fig. 3. The first 6 wing mode shapes of the baseline configuration

\subsection{Influence of Composite Orientation}

The results presented in Figure 4 below elaborates a log-log plot of bending moment PSD against the frequency ranging from 0 to $100 \mathrm{~Hz}$. It is clear that the bending moment PSD illustrates 
peaks at the natural frequencies. The highest peak response of the wing root is seen at approximately $0 \mathrm{~Hz}$. This shows a very low value of the bending moment PSD for large frequency interval relative to the low frequency domain.

Following the results of the basic orientation, the laminate is rearranged to check the effect of the composite orientations towards bending moments PSD. The wing configuration is retained as tapered and straight in order to verify the effect of the composite orientation only towards the bending moment PSD.

One of the most fundamental ideas in the aircraft design is to reduce the wing root bending moment. Therefore, changing the orientation of the composite layer has shown a slight improvement in the bending moment PSD as indicated by Figure 4 . Figure 4 is generated by reducing the maximum value of the horizontal axis, this helps in visualizing the changes of the bending moment amongst the three orientations. Following illustrations below, it is vividly clear that baseline orientation reduces the bending moment PSD slightly within the lowest frequencies range. The bending moment PSD has the maximum values at the lowest frequencies and thus reducing its magnitude within this range will help drastically reduce the overall bending moment PSD. From the results above, the optimum orientation was the baseline and thus used in the other analysis.

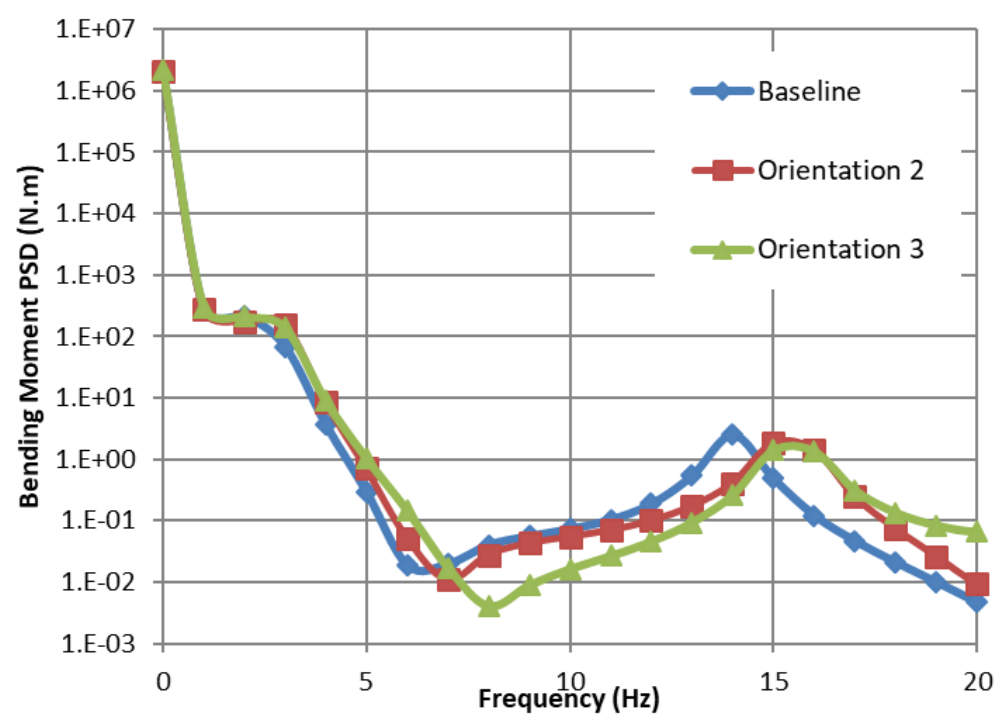

Fig. 4. Comparison of the PSD bending moment of the three laminate orientations

\subsection{Influence of Wing configurations}

The configuration of different wings has varies effects towards the performance of the aircraft which includes reducing the velocity along the wing or even drop in the drag forces applied on the wing surface.

Following Figure 5 below, all the four types of the dihedral angle are shown and compared with the baseline wing. The values are approximately the same throughout the graph with the exception of few points where the fluctuations were seen. It can be clearly seen and summarize that dihedral anhedral wings have negligible effects on the bending moment PSD. 


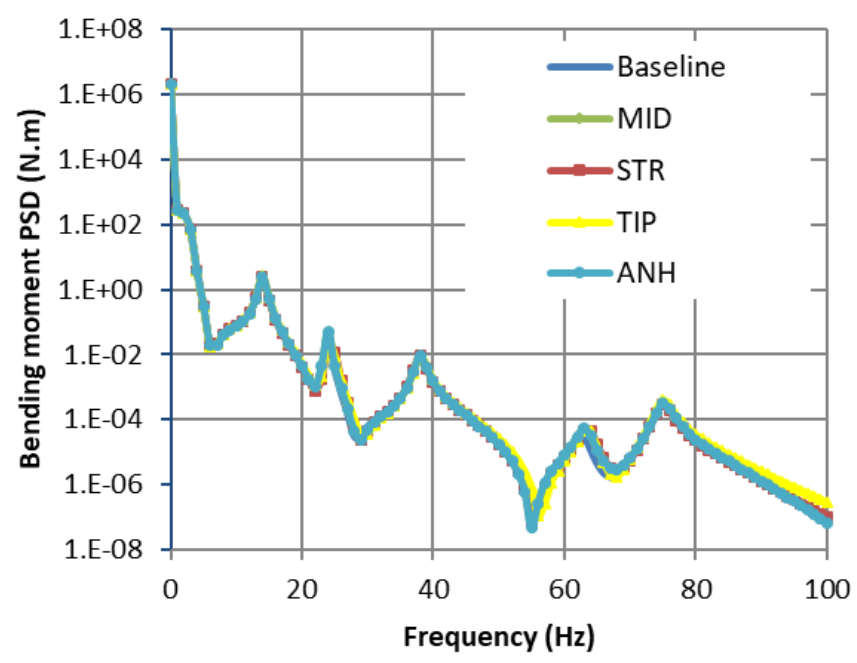

(a)

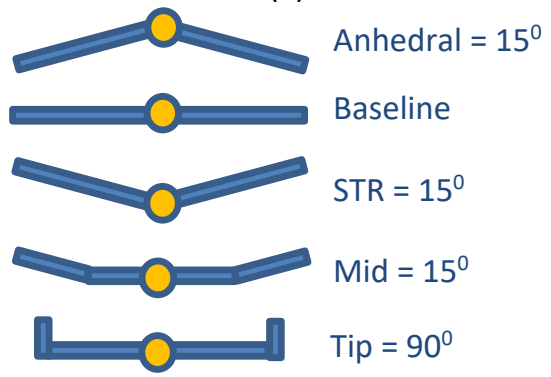

(b)

Fig. 5. (a) Influence of dihedral wing angle on bending moment PSD, (b) Front view of the aircraft with various wing dihedral angles

In this section, swept wing configuration was introduced in order to find out its influence on the wing root bending moment PSD. Moreover, three different angles were used for the swept back wing to perform the analysis including $15^{\circ}, 30^{\circ}$ and $45^{\circ}$ whereas $15^{\circ}$ and $30^{\circ}$ only used for the swept forward configuration. Furthermore, varying the angle of sweep, gives an idea on the influence of the swept wing as its angle is increased or decreased. In addition, the three composite orientation discussions earlier were also tested using swept back wing of $45^{\circ}$. This was done to reconfirm the optimum choice of the angle orientation.

Following Figure 6 below, there is an improvement in the lower frequency range since the bending moment PSD decreased. Decreasing the bending moment PSD at the lower frequency range is very significant since the values are very large. Therefore, this will have a decisive performance. However, there is insignificant improvement within the highest frequency range.

One of the most important observations made from the graph is the drop of the bending moment PSD as the swept back angle is increased from $15^{\circ}$ to $45^{\circ}$. Therefore, it vividly clear that swept back wing has an influence towards the bending moment PSD. Moreover, we are having a drastic drop from $0 \mathrm{~Hz}$ to about $6 \mathrm{~Hz}$ which is the range of the highest value of bending moment PSD. The maximum value of the bending moment PSD dropped slightly for the first configuration, almost by a magnitude of 10 for the second arrangement and a drastic drop by a value of almost 100 for the third layout of the swept wing. It is very clear that as the swept angle is increased, the bending moment PSD drops. 


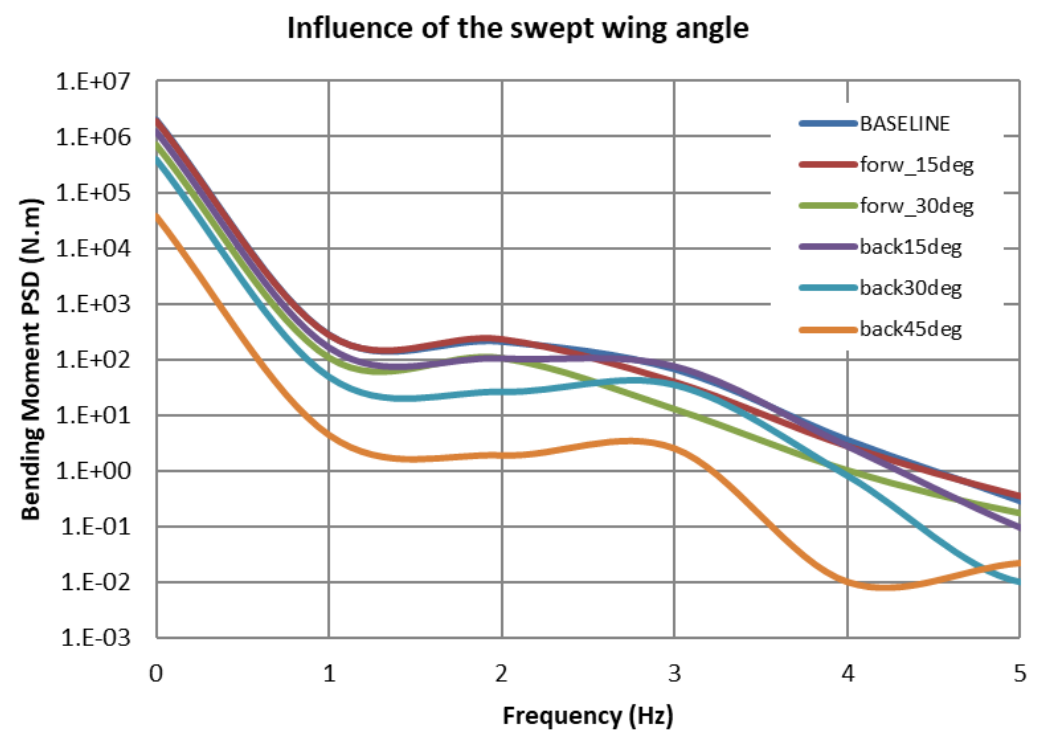

Fig. 6. Influence of the swept wing angle on bending moment PSD

In addition, swept forward wing shows a slight drop of the bending moment PSD when the sweep angle is increased. The first configuration drops the maximum bending moment value by less than 1 as compared to the second layout whereby the drop was roughly 5 . Therefore, we can affirm that increasing the sweep angle of the swept forward wing will lower the bending moment PSD slightly.

Furthermore, this elaborates the significant of the swept wing configuration towards reducing the bending moment PSD especially swept back wing arrangement. The third layout of swept back wing $\left(45^{\circ}\right)$ configuration showed a drastic improvement on the wing performance when it comes to bending moment PSD.

\section{Conclusions}

A brief overview of gust load alleviation has been presented. The present work shows the influence of the gust load on the wing root bending moment for various wing dihedral angles, wing sweep angles, and wing composite layer arrangements. The baseline of the wing configuration used in the present work is the Kim-Hwang's wing baseline configurations which has no dihedral and zero sweep angle. In the present work, the Kim-Hwang wing baseline configuration is modified by the following:

I. Changing the dihedral angle of the wing parts.

II. Changing the sweep angle of the wing.

Validation of the procedure by comparison to the Kim-Hwang baseline configuration shows well agreement between the wing's natural frequency results where the highest percentage difference between the results is roughly $3.8 \%$.

The present work shows that, for the present wing configuration, the influence of the wing dihedral angle is insignificant for the gust load alleviation. In contrast, it is found that the wing sweep angle significantly affects the bending moment at the wing root due to the gust load, i.e. the higher the sweep angle, the lower the bending moment. It is revealed also that backward swept wing is better than forward swept wing for the gust load alleviation. Particularly for the $45^{\circ}$ sweptback angle, the drop of the root bending moment is very significant.

Above all, some of the suggestions were noted during the study as follow: 
I. In this present work, flutter analysis was not conducted in detail and presented. Therefore, further study on the aeroelastic flutter would be recommended.

II. The sweep angles were restricted to only three angles. It is proposed to add more detail angles into the analysis to find the optimum one.

III. The variation of the other parameters such as angle of attack and control surface deflection can be included in the analysis.

\section{Acknowledgement}

The support of Malaysian Ministry of Higher Education through International Islamic University Malaysia under the research grant FRGS17-036-0602 is gratefully acknowledged. The authors would like to thank STRIDE to give permission to use NASTRAN in their facility.

\section{References}

[1] Cook, Robert G., Rafael Palacios, and Paul Goulart. "Robust gust alleviation and stabilization of very flexible aircraft." AIAA journal 51, no. 2 (2013): 330-340.

https://doi.org/10.2514/1.j051697

[2] Dillsaver, Matthew, Carlos Cesnik, and llya Kolmanovsky. "Gust response sensitivity characteristics of very flexible aircraft." In AIAA Atmospheric Flight Mechanics Conference, p. 4576. 2012. https://doi.org/10.2514/6.2012-4576

[3] Weisshaar, T. "Static aeroelastic behavior of an adaptive laminated piezoelectric composite wing." In 31st Structures, Structural Dynamics and Materials Conference, p. 1078. 1990.

https://doi.org/10.2514/6.1990-1078

[4] Gauthier Perron, Sebastien, and Mark Drela. "Passive gust load alleviation through bend-twist coupling of composite beams on typical commercial airplane wings." In 54th AIAA/ASME/ASCE/AHS/ASC Structures, Structural Dynamics, and Materials Conference, p. 1490. 2013. https://doi.org/10.2514/6.2013-1490

[5] Guo, Shijun, Daochun Li, and Y. Liu. "Multi-objective optimization of a composite wing subject to strength and aeroelastic constraints." Proceedings of the Institution of Mechanical Engineers, Part G: Journal of Aerospace Engineering 226, no. 9 (2012): 1095-1106. https://doi.org/10.1177/0954410011417789

[6] Guo, Shijun, De Los Monteros, Jaime Espinosa, and Ying Liu. "Gust alleviation of a large aircraft with a passive twist wingtip." Aerospace 2, no. 2 (2015): 135-154. https://doi.org/10.3390/aerospace2020135

[7] Hoblit, Frederic M. (2012). Gust Loads on Aircraft: Concepts and Applications. AIAA Education Series. https://doi.org/10.2514/4.861888

[8] Kim, Tae-Uk, and In Hee Hwang. "Optimal design of composite wing subjected to gust loads." Computers \& structures 83, no. 19-20 (2005): 1546-1554.

https://doi.org/10.1016/j.compstruc.2005.02.002

[9] McLean, D. "Gust-alleviation control systems for aircraft." In Proceedings of the Institution of Electrical Engineers, vol. 125, no. 7, pp. 675-685. IET Digital Library, 1978. https://doi.org/10.1049/piee.1978.0159

[10] Regulations, Federal Aviation. "Part 25-Airworthiness standards: Transport category airplanes." Federal Aviation Administration (FAA), USA (1970).

[11] Rodden, William P., and Erwin H. Johnson. MSC/NASTRAN aeroelastic analysis: user's guide; Version 68. MacNealSchwendler Corporation, 1994.

[12] Su, Weihua, and Carlos ES Cesnik. "Dynamic response of highly flexible flying wings." AIAA journal 49, no. 2 (2011): 324-339. https://doi.org/10.2514/1.j050496

[13] Atmosphere, US Standard. "National oceanic and atmospheric administration." National Aeronautics and Space Administration, United States Air Force, Washington, DC (1976).

[14] Lin, Charrissa Y., Edward F. Crawley, and Jennifer Heeg. "Open-and closed-loop results of a strain-actuated active aeroelastic wing." Journal of Aircraft 33, no. 5 (1996): 987-994. https://doi.org/10.2514/3.47045 
[15] Wright, Jan R., and Jonathan E. Cooper. Introduction to Aircraft Aeroelasticity and Loads. $2^{\text {nd }}$ Edition. Wiley, West Sussex, UK, 2015.

https://doi.org/10.1002/9781118700440

[16] Yu, Yang, Zhengjie Wang, and Shijun Guo. "Efficient method for aeroelastic tailoring of composite wing to minimize gust response." International Journal of Aerospace Engineering 2017 (2017): 1-12. https://doi.org/10.1155/2017/159

[17] Tajuddin, Nurulhuda, Shabudin Mat, Mazuriah Said, and Shumaimi Mansor. "Flow characteristic of blunt-edged delta wing at high angle of attack." Journal of Advanced Research in Fluid Mechanics and Thermal Sciences 39, no. 1 (2017): 17-25.

[18] Munshi, Adnan, Erwin Sulaeman, Norfazzila Omar, and Mohammad Yeakub Ali. "CFD Analysis on the Effect of Winglet Cant Angle on Aerodynamics of ONERA M6 Wing." Journal of Advanced Research in Fluid Mechanics and Thermal Sciences 45, no. 1 (2018): 44-54. 